\title{
Reconstrucción tridimensional in vitro de mucosa vesical humana
}

\author{
E. de Diego Rodríguez, A. Roca Edreira*, A Villanueva Peña, A. Meana Infiesta***, \\ S. Gómez Llames***, B. Martín García*, J.Mª Gómez Ortega** \\ Servicio de Urología y **Servicio de Anatomía Patológica. Hospital Comarcal de Laredo (Cantabria). \\ * Servicio de Urología Hospital Universitario Marques de Valdecilla. Santander. (Cantabria). \\ *** Centro Comunitario de Sangre y Tejidos del Principado De Asturias. Oviedo. (Asturias).
}

Actas Urol Esp 2006; 30 (2): 195-205

\section{RESUMEN}

RECONSTRUCCIÓN TRIDIMENSIONAL IN VITRO DE MUCOSA VESICAL HUMANA.

Objetivo: Aplicar las técnicas de cultivo in vitro de queratinocitos así como los principios de la ingeniería tisular al epitelio urinario humano, con el fin de reconstruir tridimensionalmente una mucosa vesical humana in vitro, apta para trasplantar.

Material y Métodos: Se obtuvieron muestras de mucosa vesical de pacientes programados para cirugía abierta de próstata, previo consentimiento de los mismos, las cuales fueron cultivadas in vitro, para proceder posteriormente al estudio histomorfológico de los tejidos obtenidos.

Resultados: Se obtuvo un tejido tridimensional compuesto por una submucosa bioartificial a base de un gel de fibrina y fibroblastos, sobre la que descansan las células uroepiteliales, pudiendo utilizar una malla de ácido poliglicólico, que facilite la manipulación de la mucosa y el posterior injerto de la misma. El tejido obtenido tenía el aspecto de un epitelio inmaduro con muy escasa reacción a citoqueratinas, sin poderse demostrar inmunohistoquímicamente el desarrollo de una membrana basal.

Conclusiones: Las técnicas de cultivo in vitro de queratinocitos son aplicables a otros epitelios, entre ellos el urotelio humano. En un periodo de tiempo relativamente corto se puede obtener un tejido in vitro tridimensional apto para trasplantar, precisando posiblemente de las interacciones con el lecho receptor para poder madurar.

Palabras Clave: Cultivo in vitro. Urotelio. Ingeniería tisular.

\section{ABSTRACT}

IN VITRO THREE-DIMENSIONAL RECONSTRUCTION OF HUMAN BLADDER MUCOSA.

Objetive: The purpose of this study is to apply the in vitro keratinocyte culture techniques and the tissue engineering principles to human urothelium, to reconstruct an in vitro three-dimensional human bladder mucosa, suitable for grafting.

Material and Methods: Biopsy specimens of human bladder mucosa were obtained from patients undergoing suprapubic prostatectomy, in vitro cultured and finally, an immunohistochemical study was made.

Results: A three-dimensional in vitro tissue was obtained, composed of a bio-artificial submucosa (fibrin gel and fibroblast) where the uroepithelial cells were seeding. We used a biodegradable polyglycolic acid mesh to facilitate the tissue manipulation and implantation.

An immature epithelium was obtained with a weak immunostaining to cytokeratins. The immunohistochemical study could not demonstrate the development of basement membrane.

Conclusions: In vitro keratinocyte culture techniques could be applied to other epithelial tissues like the urothelium. We obtained a three-dimensional in vitro tissue suitable for grafting in a relatively short time, which needs the matrix interactions in order to mature. 
$\mathrm{E}^{1}$ aparato genitourinario está expuesto a un gran número de lesiones ya desde el inicio de su desarrollo embriológico. Además de las malformaciones congénitas, otros procesos como neoplasias, infecciones, traumatismos o lesiones iatrogénicas pueden provocar alteraciones o pérdidas de los órganos genitourinarios, que hagan necesaria su reconstrucción o restitución ${ }^{1-5}$.

Tradicionalmente la cirugía reconstructiva del aparto urinario se ha enfrentado a la falta de tejidos urológicos nativos, lo que ha obligado a la utilización de tejidos heterólogos (piel, tracto gastro-intestinal, mucosa bucal, etc.) o materiales sintéticos, con no siempre buenos resultados.

El uso de tejidos no urológicos, como por ejemplo el tracto gastro-intestinal, es la técnica de elección universalmente aceptada a falta de una alternativa mejor para la reconstrucción la vía urinaria, a pesar de sus conocidas complicaciones: infección, formación de moco y litiasis, alteraciones metabólicas o desarrollo de neoplasias ${ }^{6-9}$.

La utilización de otros tejidos como la piel y mucosa prepucial o el epitelio vesical o bucal ofrecen resultados aceptables con el serio inconveniente de no siempre disponer de los mismos o hacerlo en cantidades limitadas ${ }^{10,11}$.

Por otra parte, el uso de materiales sintéticos persistentemente ha fracasado, en gran parte debido a las particulares características del aparato urinario, siendo una constante la presencia de infección, la formación de litiasis o el rechazo del material ${ }^{12,13}$.

Estas limitaciones han obligado a los investigadores a una búsqueda incesante de nuevas alternativas.

Recientemente se introduce un nuevo concepto en la cirugía reconstructiva génito-urinaria al intentar aplicar las técnicas del cultivo celular y de la ingeniería de tejidos, con el fin de obtener un tejido urológico bioartificial útil para trasplantar, que evitase así los problemas originados por el uso de tejidos heterólogos o materiales sintéti$\cos ^{14-18}$.

Basándonos en la amplia experiencia de otros autores $^{1-5,14-18}$ y en la nuestra propia con el cultivo in vitro de urotelio en el animal de experimentación ${ }^{19}$, pretendimos reconstruir un equivalente uroepitelial completo in vitro, aplicando los principios del cultivo celular y de la ingeniería de tejidos al urotelio humano, para poder obtener así un tejido viable, de constitución tridimensional, fácil de manejar, y que en futuros trabajos nos permita demostrar su viabilidad como injerto libre y por tanto poder establecer con el tiempo posibles aplicaciones clínicas.

\section{MATERIAL Y METODOS}

Se obtuvieron muestras de mucosa vesical de 5 pacientes que iban a ser sometidos a adenomectomía transvesical, previo consentimiento escrito de los mismos, sin realizarse procedimiento alguno ajeno al acto quirúrgico. El tamaño de las muestras en ningún caso fue superior a $1 \mathrm{~cm}^{2}$.

Fueron desestimados pacientes portadores de sonda uretral, litiasis vesical, enfermedades del urotelio (cistitis, neoplasias) o infecciones urinarias previamente demostradas, condiciones todas ellas que pudiesen alterar el cultivo in vitro de la muestra.

Las biopsias fueron depositadas en medio de cultivo para su posterior traslado al laboratorio.

La metodología utilizada fue prácticamente la misma que para el cultivo de urotelio en al animal de experimentación ${ }^{19}$, como a continuación se detalla y esquematiza (Fig. 1).

\section{PROCESAMIENTO DE LAS MUESTRAS}

A la llegada de la biopsia de mucosa vesical al laboratorio se procede a la retirada del medio de transporte, (medio Eagle modificado de Dulbecco (DMEM) suplementado con antibióticos). Se depositó la muestra sobre una placa de Petri para proceder a su lavado con solución de tripsina /ácido etilendiaminotetracético (tripsina / EDTA) estéril y a continuación se troceó finamente la mucosa hasta obtener pequeños fragmentos de tejido.

Seguidamente la muestra fue depositada en un frasco con agitador magnético estéril, añadiéndose aproximadamente $50 \mathrm{ml}$ de solución de tripsina/EDTA y se incuba a $37^{\circ} \mathrm{C}$, bajo agitación, durante 30 minutos.

Se procedió a la agitación de los fragmentos de mucosa, dejándose decantar éstos y se recogió la tripsina pasándose a un tubo cónico de $15 \mathrm{ml}$. Se añadieron $25 \mathrm{ml}$ más de tripsina fresca al frasco agitador que contiene los fragmentos de mucosa y se incubaron nuevamente a $37^{\circ} \mathrm{C}$ durante 30 minutos. 


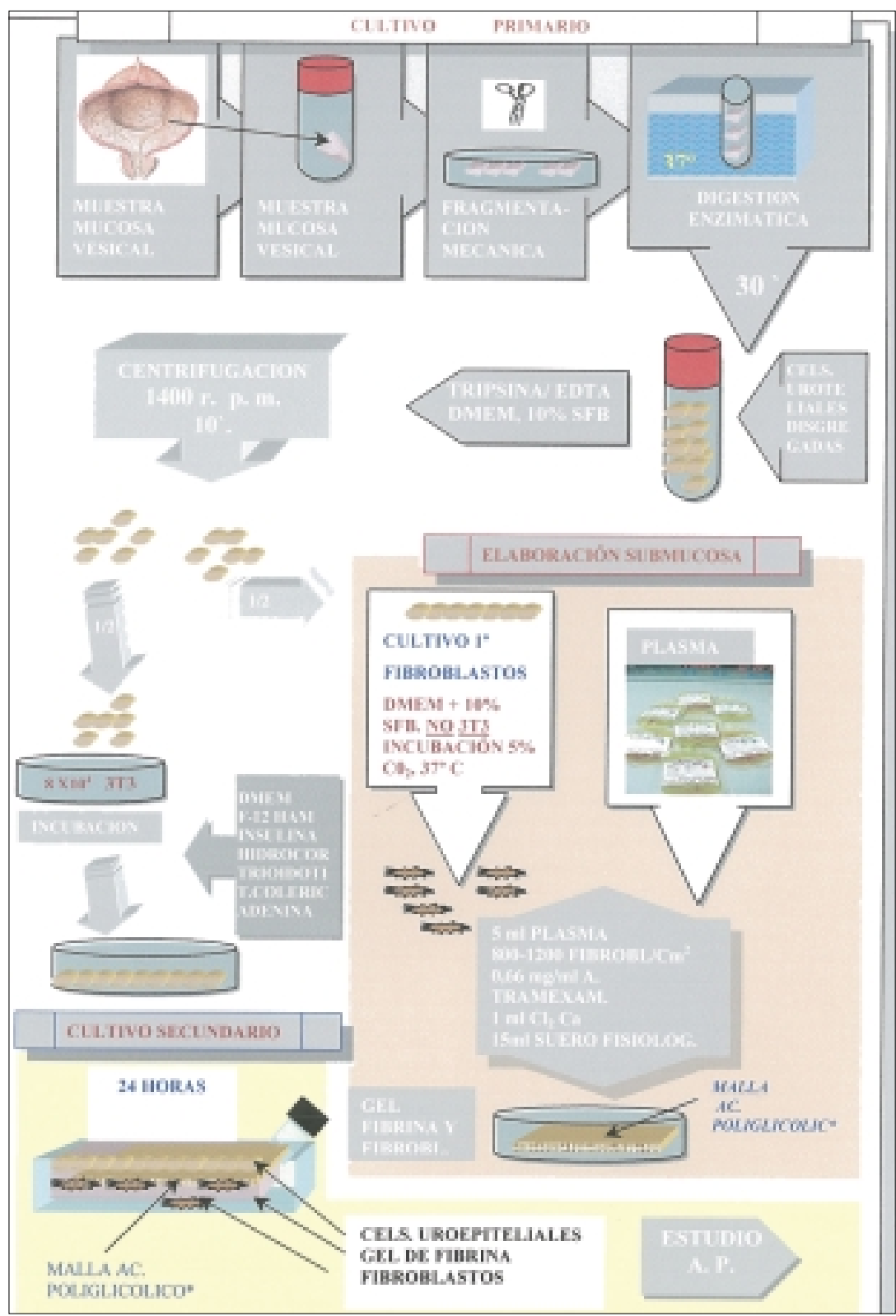

FIGURA 1. Metodologia del cultivo in vitro de mucosa vesical humana.

\section{CULTIVO PRIMARIO DE CELULAS UROEPITELIALES}

De las células obtenidas en el procesamiento de la muestra se seleccionaron aproximadamente la mitad de ellas para su siembra en un pocillo de cultivo celular de $6 \mathrm{~cm}^{2}$ de superficie en presencia de una capa alimentadora de $5 \mathrm{x}$ $10^{5}$ células 3T3 (fibroblastos de ratón irradiados letalmente $(6000$ rads), ECACC 85022108), lo que equivale a unas $8 \times 10^{4}$ células $3 \mathrm{~T} 3 / \mathrm{cm}^{2}$.

Para la siembra celular se utilizó medio de cultivo para queratinocitos, cuya composición es a base de medio Eagle modificado de Dulbecco (DMEM) (Biochrom KG) y Ham F-12 (Biochrom KG) en proporción 3:1, suplementado con $10 \%$ de suero fetal bovino (Biochrom $\mathrm{KG}), 5 \mu / \mathrm{ml}$ de insulina (Sigma), 0,4 $\mu / \mathrm{ml}$ de hidrocortisona (Sigma), 1,3 ng / $\mathrm{ml}$ de triyodotironina (Sigma), $8 \mathrm{ng} / \mathrm{ml}$ de toxina colérica (Sigma) y $24 \mu / \mathrm{ml}$ de adenina (Sigma).

Las células epiteliales sembradas en este medio se mantuvieron en incubación en estufa de $\mathrm{CO}_{2}$ al $5 \%$ a $37^{\circ} \mathrm{C}$.

$\mathrm{El}$ medio de cultivo fue reemplazado cada 72 horas; en el primer cambio se añadió al medio 10 $\mathrm{ng} / \mathrm{ml}$ de factor de crecimiento epidérmico (EGF) (Austral Biologicals), repitiéndose la misma operación hasta que las células estuviesen próximas a la confluencia.

Cuando las células epiteliales fueron confluentes se trataron con tripsina /EDTA estéril para despegar las células de la superficie del frasco de cultivo.

Una vez individualizadas las células la tripsina fue neutralizada mediante la adicción volumen a volumen de medio de cultivo suplementado con un $10 \%$ de suero fetal bovino y se centrifugan a 1400 r.p.m. durante 10 minutos. 


\section{ELABORACIÓN DE LA SUBMUCOSA}

\section{ARTIFICIAL}

Cultivo primario de fibroblastos

Para el cultivo primario de fibroblastos se utilizaron la otra mitad de las células obtenidas inicialmente en el procesamiento de la muestra; en un principio se sembraron aproximadamente $10^{5}$ células en un pocillo de cultivo celular de $6 \mathrm{~cm}^{2}$, en ausencia de células cebadoras 3T3.

Como medio de cultivo se utilizó DMEM suplementado con un $10 \%$ de suero fetal bovino. Los cultivos se mantuvieron en estufa de $\mathrm{CO}_{2}$ al $5 \%$ a $37^{\circ} \mathrm{C}$.

\section{Obtención del gel de fibrina-fibroblastos}

La fuente de fibrina se obtuvo a partir de plasma congelado procedente del banco de sangre.

Los geles para una placa de $66 \mathrm{~cm}^{2}$ de superficie se prepararon con:

- $5 \mathrm{ml}$ de plasma.

- 800-1200 fibroblastos $/ \mathrm{cm}^{2}$.

- 0,66 $\mathrm{mg} / \mathrm{ml}$ de ácido tranexámico (Amchafibrin ${ }^{\circledR}$, Fides-Rottapharm).

- $1 \mathrm{ml}$ de cloruro cálcico (Sigma) al 1\% en suero fisiológico.

- Se completa con suero fisiológico hasta un volumen de $15 \mathrm{ml}$.

La mezcla se depositó en la estufa a $37^{\circ} \mathrm{C}$ con un $5 \%$ de $\mathrm{CO}_{2}$ entre 30 minutos y una hora para permitir el secado y coagulación de los geles; transcurrido este tiempo se añadió $10 \mathrm{ml}$ de medio de cultivo para queratinocitos sin EGF.

Para mejorar la consistencia y manipulación del tejido obtenido se puede utilizar una malla de poliglactin 910 (Vicril $^{\circledR}$ Jhonson \& Jhonson, Intl. Brussels, Belgium), la cual se coloca en una placa de Petri y sobre ella se deposita el gel esperando 24 horas hasta la realización del cultivo secundario; en este trabajo no utilizamos inicialmente el soporte para poder estudiar mejor la estructura conseguida.

\section{CULTIVO SECUNDARIO DE CELULAS UROEPITELIALES SOBRE SUBMUCOSA ARTIFICIAL}

Las células obtenidas en cultivo primario son lavadas con tripsina /EDTA estéril e incubadas a $37^{\circ} \mathrm{C}$ hasta conse- guir que las células se despeguen, posteriormente se neutraliza la tripsina mediante la adicción volumen a volumen de medio de cultivo para queratinocitos. Se procede centrifugación a 1400 r.p.m. y el pellet obtenido se resuspende en $5-10 \mathrm{ml}$ de medio de cultivo de queratinocitos sin EGF.

Estas células se siembran sobre la submucosa artificial transcurridas 24 horas de la elaboración de la misma, en ausencia de capa alimentadora de células 3T3. El medio de cultivo se cambió cada 72 horas y el control del cultivo se realizó mediante microscopio de luz invertida.

La estructura del tejido obtenido constaba por tanto de una capa de células uroepiteliales que descansan sobre una submucosa bioartificial compuesta de gel de fibrina y fibroblastos, a la que se puede añadir el soporte mediante la malla de ácido poliglicólico (Fig. 2).

Las células uroepiteliales sembradas sobre la submucosa bioartificial se mantuvieron en cultivo hasta alcanzar la confluencia, para posteriormente proceder a su estudio anátomo-patológico.

\section{ESTUDIO ANÁTOMO-PATOLÓGICO}

A las 24-48 horas de alcanzar las células la confluencia sobre la submucosa creada se procedió a su estudio histológico.

Las muestras de tejido fueron fijadas en formol al $10 \%$ y sometidas al procesamiento habitual para ser incluidas en parafina y posteriormente teñidas con la técnica de hematoxilinaeosina.

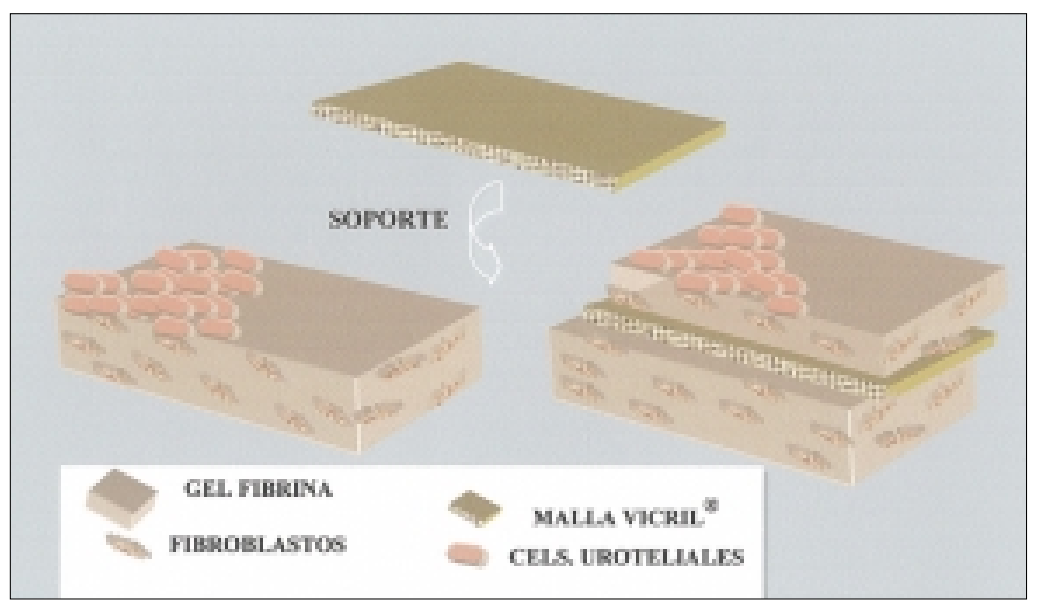

FIGURA 2. Estructura tridimensional del tejido in vitro al que se le puede dotar de un soporte fisico (malla de Vicril $\left.{ }^{\circledR}\right)$. 
Se realizaron tinciones inmunohistoquímicas mediante el inmunoteñidor automático TechMate TM 500-520 (Biotech Solutions, Santa Bárbara, California, USA), utilizando los anticuerpos monoclonales: anticuerpo monoclonal Panqueratina (CK 22) $\left(\right.$ Dako ${ }^{\circledR}$ Glostrup. Dinamarca), anticuerpo monoclonal colágeno IV (C IV) (Dako ${ }^{\circledR}$ Glostrup. Dinamarca), anticuerpo monoclonal laminina. (Dako ${ }^{\circledR}$ Glostrup. Dinamarca).

\section{RESULTADOS}

\section{CULTIVO IN VITRO DE MUCOSA VESICAL} HUMANA

\section{RECOLECCION CELULAR}

Las muestras se procesaron siguiendo el mismo método de disgregación celular enzimática, obteniéndose un número suficiente de células para su expansión en cultivo primario. (Tabla 1)

Destinamos la mitad de las células procedentes del tratamiento de la muestra para su cultivo primario y la otra mitad para cultivo primario de fibroblastos al observar un rápido crecimiento de las células uroteliales, bastante superior al presentado por queratinocitos humanos en las mismas condiciones de cultivo.

\section{CULTIVO PRIMARIO DE CELULAS UROEPITELIALES HUMANAS}

Se pudo apreciar el inicio de la formación de colonias uroepiteliales aproximadamente hacia el $4^{\circ}$ día de cultivo, siendo aún predominantes las células 3T3, las cuales progresivamente a lo largo de los días de cultivo fueron rechazadas a la periferia hasta llegar a desaparecer cuando el cultivo fue confluente (Fig. 3).

Los cultivos primarios de las células alcanzaron la confluencia entre los 10 y 13 días (Tabla 1).

\section{CULTIVO SECUNDARIO SOBRE GEL DE FIBRINA-FIBROBLASTOS \\ Elaboración del gel de fibrina}

Los geles de fibrina se elaboraron a partir de plasma congelado disponible en cualquier banco de sangre (Fig. 4).

Los fibroblastos fueron obtenidos mediante el cultivo primario de aproximadamente la mitad de las células conseguidas en el procesamiento de las muestras, utilizando como medio de cultivo DMEM suplementado con un $10 \%$ de suero fetal

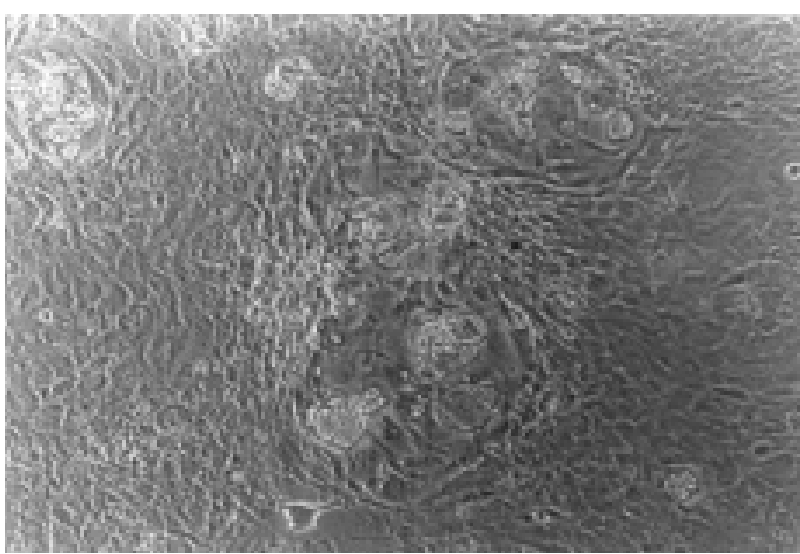

FIGURA 3. Cultivo primario de células uroepiteliales humanas. H.E. $100 x$.

bovino, manteniendo los cultivos en estufa de $\mathrm{CO} 2$ al $5 \%$ a $37^{\circ} \mathrm{C}$, en ausencia de células 3T3; en estas condiciones de cultivo únicamente se obtiene una proliferación fibroblástica en los medios (Fig. 5).

No hubo problema en la confección de las submucosas en ninguno de los casos.

\section{Cultivo secundario}

El cultivo secundario se realizó al alcanzar la confluencia el cultivo primario (10-13 días) y 24 horas después de haberse elaborado la submucosa.

En esta caso no utilizamos la malla de ácido poliglicólico para mejorar la consistencia al no ser injertado el tejido posteriormente por lo que la submucosa constaba de gel de fibrina y fibroblastos.

La confluencia celular de los cultivos secundarios se alcanzó entre 10 y 13 días, de forma tal que el tiempo necesario para la obtención de una mucosa bioartificial completa osciló entre 22 y 26 días. (Tabla 1).

En ninguno de los cultivos realizados se apreció retracción significativa del gel de fibrina.

\section{ESTUDIO HISTOMORFOLÓGICO}

$\mathrm{El}$ aspecto histológico de los cultivos era inicialmente el de una monocapa de células de estirpe epitelial que descasan sobre un estroma fibrinoide con presencia de fibroblastos. (Fig. 6 y 7).

Manteniendo las condiciones de cultivo en días sucesivos se pudo apreciar en algunas zonas un epitelio pseudoestratificado, mostrando las 
Tabla 1

Resultados recolección celular, cultivo primario y secundario de urotelio humano

\begin{tabular}{|c|c|c|c|c|c|c|c|}
\hline \multirow[t]{2}{*}{ Muestra } & \multirow{2}{*}{$\begin{array}{l}\text { Número } \\
\text { células } \\
\text { obtenidas }\end{array}$} & \multicolumn{2}{|c|}{ Cultivo primario } & \multirow{2}{*}{$\begin{array}{c}\text { Fibroblastos } \\
\text { Células } \\
\text { cultivadas }\end{array}$} & \multicolumn{3}{|c|}{ Cultivo secundario } \\
\hline & & $\begin{array}{c}\text { Células } \\
\text { cultivadas }\end{array}$ & $\begin{array}{c}\text { Días } \\
\text { cultivo }\end{array}$ & & $\begin{array}{l}\text { Días } \\
\text { cultivo }\end{array}$ & $\begin{array}{l}\text { Total } \\
\text { días } \\
\text { cultivo }\end{array}$ & Viabilidad \\
\hline $\mathrm{M}_{1}$ & 935.000 & 467.500 & 11 & 467.500 & 13 & 24 & $\checkmark$ \\
\hline $\mathrm{M}_{2}$ & 1.275 .000 & 637.500 & 11 & 637.500 & 11 & 22 & $\checkmark$ \\
\hline $\mathrm{M}_{3}$ & 4.350 .000 & 2.675 .000 & 10 & 2.675 .000 & 13 & 23 & $\checkmark$ \\
\hline $\mathrm{M}_{4}$ & 890.000 & 445.000 & 12 & 445.000 & 12 & 24 & $\checkmark$ \\
\hline $\mathrm{M}_{5}$ & 995.000 & 497.500 & 13 & 497.500 & 13 & 26 & $\checkmark$ \\
\hline
\end{tabular}

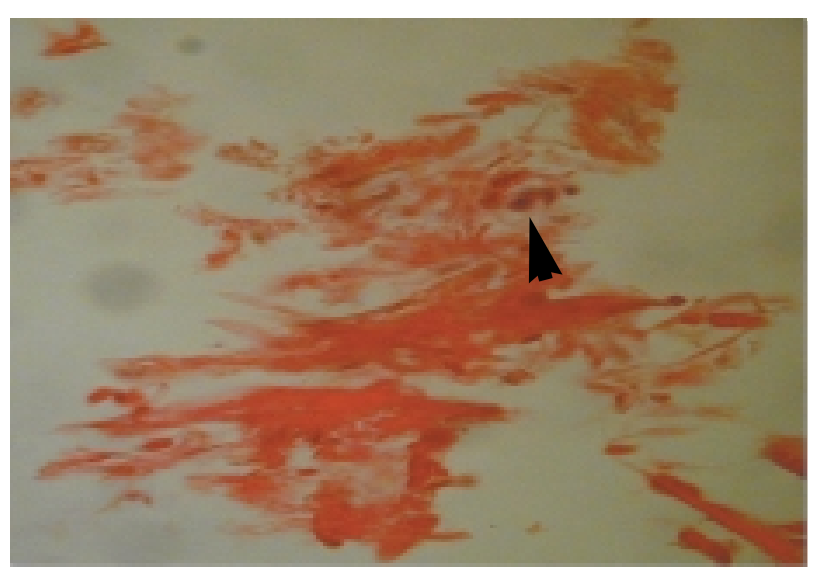

FIGURA 4. Matriz de fibrina con fibroblastos (flecha). H.E. $400 x$.

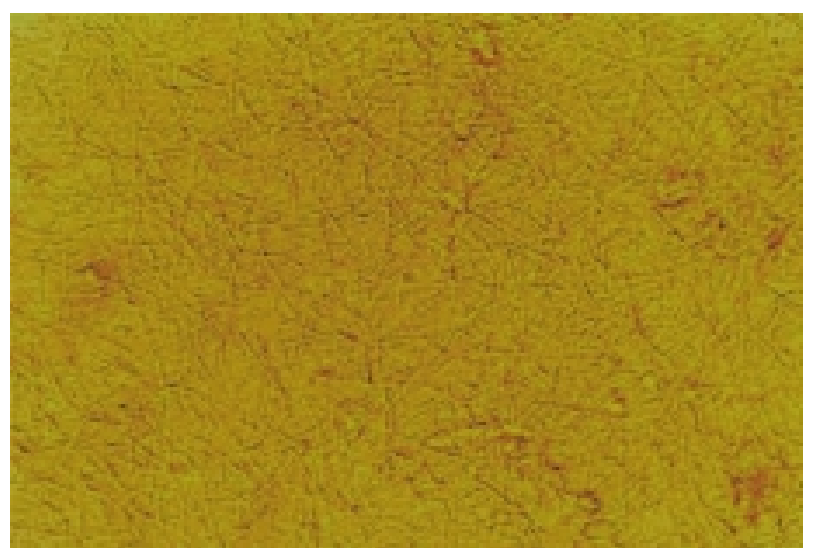

FIGURA 5. Cultivo primario de fibroblastos. 100x.

células una apariencia reactiva, con núcleos agrandados y nucleolos eosinófilos prominentes, observándose en ocasiones células multinucleadas, aumentando el número de capas celulares (Fig. 8 y 9).
La morfología celular parecía corresponder a un epitelio; en determinadas zonas fue posible identificar una cierta pseudoestratificación celular que recordaban en algún modo el aspecto histológico característico de un epitelio de transición inmaduro (Fig. 10).

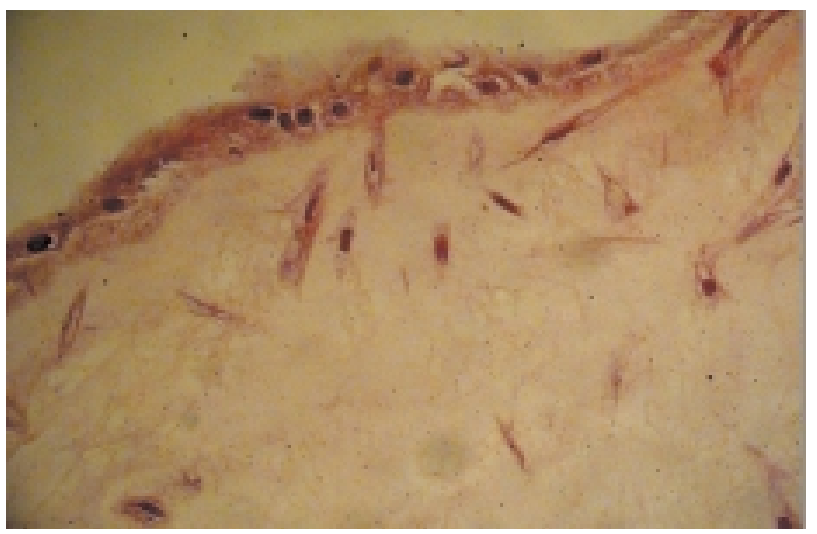

FIGURA 6. Epitelio vesical humano in vitro. (fase inicial). H.E. 100x.

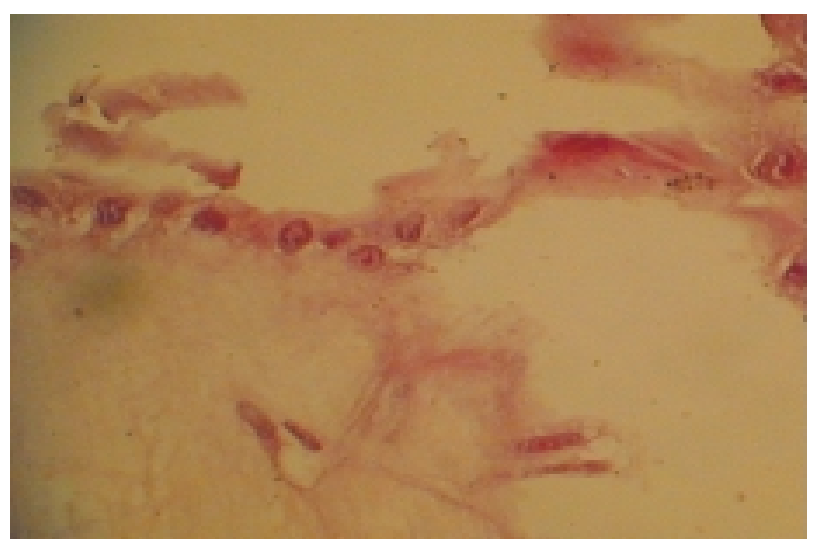

FIGURA 7. Epitelio vesical humano in vitro. (fase inicial) H.E. 400x. 


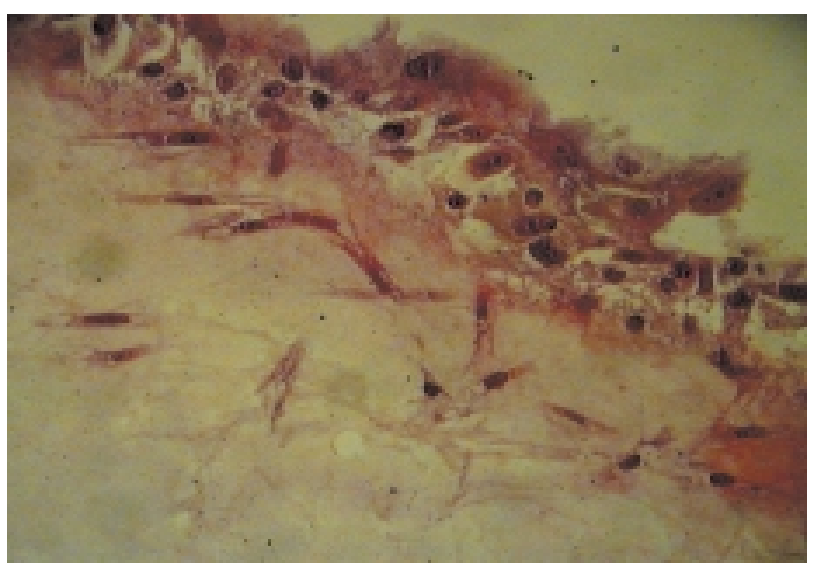

FIGURA 8. Epitelio vesical humano in vitro. (fase avanzada) H.E. 400x.

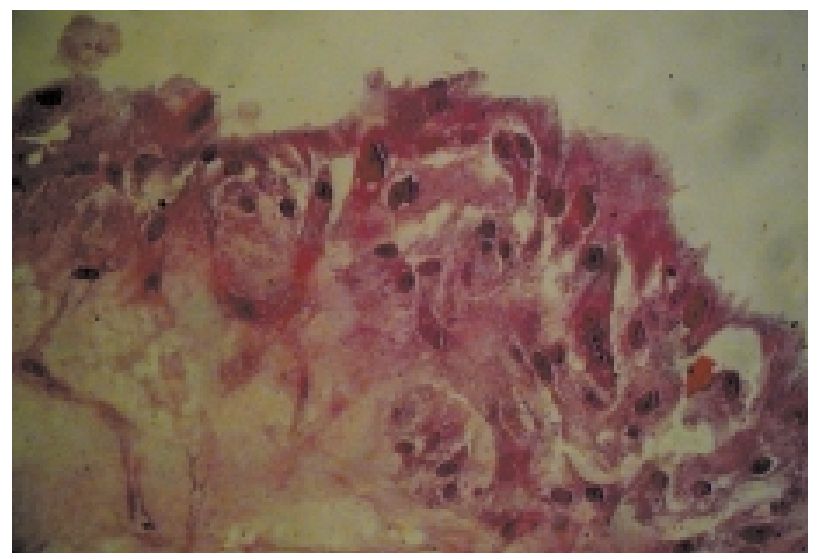

FIGURA 9. Epitelio vesical humano in vitro. (fase avanzada) H.E. 400x.

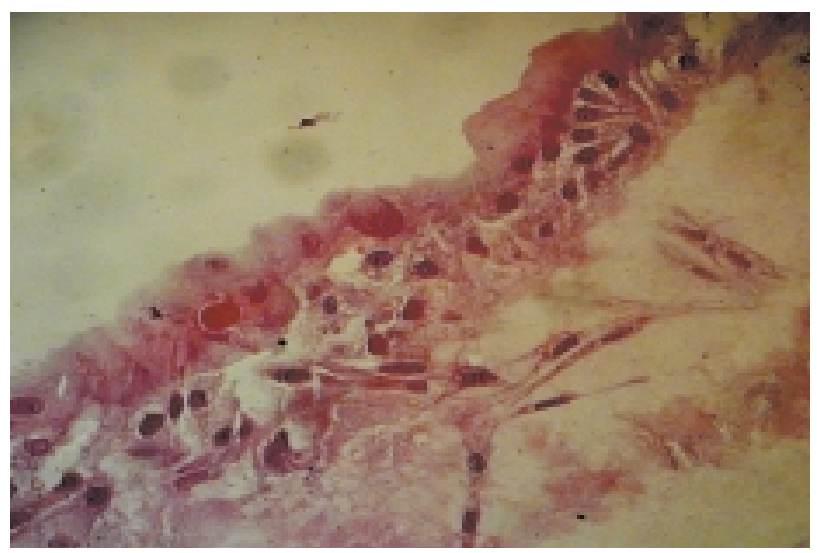

FIGURA 10. Epitelio vesical humano in vitro. (fase avanzada) H.E. 400x.

Todas las inmunotinciones realizadas resultaron negativas, exceptuando una muy leve y no significativa positividad para citoqueratinas en alguna de las muestras, sin encontrarse estructura alguna que se tiñese para colágeno IV o laminina.
Por tanto parece factible la aplicación de las técnicas de cultivo de queratinocitos a otro tipo de epitelio como es el transicional, en este caso humano, obteniéndose un tejido tridimensional, dotado de una submucosa (fibrina y fibroblastos) con capacidad presumiblemente para madurar y apto para trasplantar.

Por último señalar el difícil manejo del tejido obtenido por la frágil consistencia del mismo debido a su constitución; este inconveniente es fácilmente solucionable utilizando como soporte un polímero biodegradable que permitirá la manipulación del tejido y favorecerá su posterior injerto, como ya utilizamos experimentalmente en el conejo ${ }^{19}$.

\section{DISCUSION}

En base a los principios del cultivo celular introducidos por Reinwald y Green ${ }^{20}$ en 1970, a la amplia experiencia existente con el cultivo de queratinocitos ${ }^{21-26}$ y a los extensos trabajos sobre ingeniería tisular urológica ${ }^{2-5,14-16,18}$ pretendimos diseñar un tejido urotelial tridimensional in vitro apto para su trasplante.

Procedimos a la recolección celular utilizando el método de disgregación celular enzimática, abandonando los métodos de explante celular o dispersión mecánica, obteniendo en todos los casos un número adecuado de células viables, factor de especial importancia para asegurar el éxito del cultivo celular posterior ${ }^{14,15,27,28}$.

Para el cultivo primario se utilizó una capa de células alimentadoras o cebadoras a base de fibroblastos de ratón letalmente irradiados (células 3T3), debido a la capacidad de las mismas para estimular el crecimiento, diferenciación y adhesión de las células epiteliales así como de secretar factores de crecimiento y proteínas de matriz extracelular ${ }^{29-33}$. Existen autores ${ }^{15,27,34,35}$ que prescinden de la utilización de esta capa argumentando que el uso de células heterólogas cuya genética ha sido alterada, pudiesen interferir en el control de la replicación de las células epiteliales. La amplia experiencia existente con el uso de estas células descarta esta opción y hasta el momento no hay referencia alguna sobre este tipo de alteraciones, por otra parte en el momento que las células epiteliales confluyen y forman una capa continua, ya no es posible demostrar la 
presencia de fibroblastos. Lauer ${ }^{36}$ estudia en cultivo células epiteliales tumorales de cavidad bucal demostrando que los fibroblastos de ratón son incapaces de inducir cambios degenerativos en líneas celulares premalignas en cultivo.

Se utilizó un medio de cultivo para queratinocitos, usando de igual manera factor de crecimiento epidérmico (EGF) de comprobada eficacia para el desarrollo de los queratinocitos in vitro. En el caso del urotelio su acción es más controvertida, siendo para algunos autores el crecimiento del mismo independiente de dicho factor $^{16,27,37}$, para otros ${ }^{38,39}$ sólo concentraciones elevadas $(50 \mathrm{ng} / \mathrm{ml})$ inducen cambios morfológicos de diferenciación celular y según otros ${ }^{40,41}$ existirian EGF-likes (factor de crecimiento transformador- $\alpha$, anfiregulina, EGF-like inhibidor de heparina...) que pudiesen regular el crecimiento y diferenciación de las células uroepiteliales por mecanismos autocrinos o paracrinos no bien $\operatorname{conocidos}^{42,43}$.

Los tejidos obtenidos mediante las técnicas de cultivo in vitro mostraban un predominio de células de aspecto basal, inmaduras e indiferenciadas, con una débil o nula respuesta a citoqueratinas en parte debido a esa inmadurez y al retraso de la misma sufrido por las células por el cultivo en inmersión ${ }^{44,45}$.

Por otra parte, el estudio inmunohistoquímico para los anticuerpos colágeno IV y laminina resultaron negativos, no pudiendo identificar ninguna estructura compatible con una membrana basal; probablemente las complejas y desconocidas interacciones entre las células trasplantadas y la matriz extracelular del receptor, mediadas por factores de crecimiento y proteínas de dicha matriz puedan contribuir al desarrollo de dicha membrana basal ${ }^{46-48}$, favoreciendo además el desarrollo y diferenciación celular.

Estudios recientes sobre el cultivo in vitro de queratinocitos ${ }^{45,49-51}$ apuntan hacia la creación de una dermis bioartificial que sirva de soporte a las células epiteliales facilitando además su crecimiento y diferenciación, creándose así una estructura tridimensional.

Fujiyama $^{44}$ diseña una mucosa vesical tridimensional in vitro estableciendo la importancia de las interacciones, aún desconocidas, entre fibroblastos, matriz extracelular y células urote- liales, siendo dichas relaciones básicas para la reconstrucción e histodiferenciación del urotelio. De esta forma crea un tejido tridimensional conformado por una capa epitelial sobre una lámina propia bioartificial compuesta de gel de colágeno y fibroblastos; el tejido creado pudo mantenerse con las características de un epitelio polarizado y bien diferenciado hasta dos meses, trascurridos los cuales, la invariable contracción experimentada por el colágeno hizo inviable la mucosa.

El colágeno ha sido ampliamente utilizado como vehículo de transporte de células uroteliales cultivadas, si bien el inconveniente de la retracción que acontece con el mismo ha limitado bastante su aplicación ${ }^{44,45}$.

Basándose en la experiencia del cultivo de queratinocitos sobre matrices de fibrina ${ }^{51-53}$, se plantea la posibilidad de utilizar estos geles como soporte para el cultivo de células uroepiteliales.

Varios autores como Wechselberger ${ }^{54-56}$, Schoeller ${ }^{57,58}$, Schaefer ${ }^{59}$ o Bach ${ }^{60}$ han conseguido expandir en cultivo con éxito células uroteliales sobre matrices de fibrina, constituyendo esta proteína un adecuado soporte orgánico, no sólo físico, sino como una matriz adecuada para el desarrollo y diferenciación celular.

Uno de sus componentes fundamentales, la fibronectina, resulta a su vez uno de los constituyentes más importantes de las membranas basales de reconocida trascendencia para los epitelios $^{54,61}$.

Por otra parte se ha demostrado que los fibroblastos cultivados en el seno de geles de fibrina inducen una rápida reorganización de las fibrillas que los rodean, las cuales se reorientan en haces paralelos a la superficie del cultivo, al igual que los fibroblastos, de esta forma la contracción que experimenta el gel se produce en espesor pero no en diámetro, contrariamente a lo que sucede con los geles de colágeno.

Staack $^{62}$ pone de manifiesto la importancia de los fibroblastos en el crecimiento y diferenciación de las células uroepiteliales en cultivo, atribuyéndose la acción de los mismos a la secreción de un factor soluble no identificado probablemente especie y órgano-específico.

La fibrina para realizar los cultivos se puede obtener a partir de preparados comerciales o a partir de plasma procedente de crioprecipitados. 
Los preparados comerciales presentan el inconveniente de sufrir un procesamiento con calor, que puede afectar a proteínas (factor VIII, factor XIII, fibronectina) y factores de crecimiento presentes en los crioprecipitados, que pueden resultar beneficiosos para el desarrollo de los cultivos.

De esta forma se pudo diseñar una submucosa bioartificial conformada por un gel de fibrina y fibroblastos, sobre la cual se realizó el cultivo secundario de las células uroepiteliales, obteniéndose así una estructura tridimensional.

Debido a las dificultades presentadas para el manejo del tejido es conveniente dotar a la estructura de un soporte físico mediante una malla de ácido poliglicólico que nos permita manipular el tejido obtenido in vitro sin dificultad alguna y a su vez la biodegradación de dicho polímero provocará una respuesta angiogénica en el huésped, útil para la superviviencia del injerto una vez trasplantado ${ }^{15,63-66 .}$

\section{CONCLUSIONES}

En el presente trabajo pudimos demostrar la posibilidad de aplicar las técnicas de cultivo de tejidos, como habíamos probado en el animal de experimentación, al urotelio humano, reconstruyendo tridimensionalmente in vitro muestras de mucosa vesical.

Por una parte se procedió a diseñar un tejido subepitelial bioartificial compuesto por gel de fibrina y fibroblastos, que actuase a modo de lámina propia, la cual por su composición facilitaría el crecimiento y diferenciación de las células uroepiteliales y a su vez proporcionaría mayor consistencia a la lámina epitelial, sin experimentar retracciones como sucede con el colágeno.

Como consecuencia de los importantes problemas a la hora de manipular los tejidos obtenidos in vitro por su escasa consistencia, dada su constitución exclusivamente epitelial, se puede utilizar como soporte del cultivo una malla de ácido poliglicólico, la cual proporciona un excelente "andamiaje" al tejido cultivado obtenido facilitando enormemente su manejo, siendo posible configurar con ella diferentes formas (lámina, tubo, esfera), fenómeno interesante en la cirugía reconstructiva
Actualmente la experiencia existente dentro del cultivo in vitro de urotelio se basa en el cultivo y siembra de las células uroepiteliales disgregadas sobre polímeros biodegradables o sobre matrices orgánicas (colágeno, fibrina), para posteriormente ser devueltas al organismo donante.

Con nuestro procedimiento, desarrollamos una estructura tridimensional in vitro, previo al injerto, combinando los principios del cultivo celular al dotar al tejido de una submucosa artificial, y los de la ingeniería tisular, asociado un polímero biodegradable que sirva de soporte al cultivo, permitiendo su manipulación y facilitando su posterior injerto.

Agradecimientos. Mostrar una vez más mi agradecimiento al Centro Comunitario de Sangre y Tejidos del Principado de Asturias, donde pudimos desarrollar las técnicas de cultivo de tejidos, así como a la colaboración obtenida de la Sociedad Cántabra de Urología.

\section{REFERENCIAS}

1. Machluf M., Atala A. Tissue engineering: Emerging concepts. Graft 1998; 1: 31-37.

2. Atala. A. Tissue engineering in urologic surgery. Urol Clin North Am. 1998 Feb;25(1):39-50.

3. Atala A. Future perspectives in reconstructive surgery using tissue engineering.Urol Clin North Am. 1999 Feb;26(1):157-165.

4. Koh CJ., Atala A. Prospects for engineering the urinary tract. Nephron Exp Nephrol. 2004; 98(3): 65-70.

5. Atala A. Tissue engineering for the replacement of organ function in the genitourinary system. Am J Transplant. 2004;4 Suppl 6:58-73.

6. McDougal S.W. Metabolic complications of urinary intestinal diversion. J Urol. 1992;147(5):1199-1208

7. Nurse DE, Mundy AR. Metabolic complications of cystoplasty.. Br J Urol. 1989;63(2):165-170.

8. Blyth B, Ewalt DH, Duckett JW, Snyder HM. Lithogenic properties of enterocystoplasty. J Urol. 1992;148(2 Pt 2): 575-577;

9. Filmer Rb. Spencer Jr. Malignancies in bladder augmentations and intestinal conduits. J Urol. 1990;143(4):671-678.

10. Filipas D, Fisch M, Fichtner J, Fitzpatrick J, Berg K, Storkel S, et al. The histology and inmunohistochemistry of free buccal mucosa and full-skin grafts after exposure to urine. BJU Int. 1999;84(1):108-111.

11. Ehrlich RM, Reda EF, Koyle MA, Kogan SJ, Levitt SB. Complications of bladder mucosal graft. J Urol. 1989;142:626-627

12. Alexsandro E., Zungri E. Sustitución de la uretra con material sintético. Actas Urol Esp 2000; 24(3): 235-242.

13. Elbahnasy AM, Shalhav A, Hoenig DM, Figenshau R, Clayman RV. Bladder wall substitution with synthetic and non-intestinal organic materials. J Urol. 1998;159:628637. 
14. Atala A, Vacanti JP, Peters CA, Mandell J, Retik AB, Freeman MR. Formation of urothelial structures in vivo from dissociated cells attached to biodegradable polymer scaffolds in vitro. J Urol. 1992;148:658-662.

15. Atala A, Freeman MR, Vacanti JP, Shepard J, Retik AB. Implantation in vivo and retrieval of artificial structures consisting of rabbit and human urothelium and human bladder muscle. J Urol 1993;150:608-612.

16. Atala A. Tissue engineering in the urinary tract. Dial Ped Urol 1995;18:6-8.

17. Kaihara S, Vacanti JP. Tissue engineering: toward new solutions for transplantation and reconstructive surgery. Arch Surg. 1999;134(11):1184-1188.

18. Atala A. Construction of artificial organs and tissues using autologous cells. AUA. Update Series 2000; 19(16):122127.

19. E. De Diego Rodríguez, A. Villanueva Peña, A. Roca Edreira, B. Martín García, A. Meana Infiesta, S Gómez Llames, J. Gómez Román Estudio experimental sobre la viabilidad del injerto libre de epitelio urinario antólogo cultivado in vitro. Actas Urol Esp 2004;28(10):714-731.

20. Rheinwald JG, Green H. Serial cultivation of strains of human epidermal keratinocytes: the formation of keratinising colonies from single cells. Cell. 1975;6(3):331-343.

21. Banks-Schlegel S, Green H. Formation of epidermis by serially cultivated human epidermal cells transplanted as an epithelium to athymic mice. Transplantation 1980; 29(4):308-311.

22. Bell E, Ehrlich P, Sher S, Merill C, Sarber R, Hull B. Development and use of a living skin equivalent. Plas Reconst Surg 1981;67(3):386-392.

23. Burke JF, Yannas IV, Quinby WC Jr, Bondoc CC, Jung WK. Successful use of a physiologically acceptable artificial skin in the treatment of extensive burn injury. Ann Surg 1981;194(4):413-418.

24. Bell E, Ehrlich HP, Buttle DJ, Nakatsuji T. Living tissue formed in vitro and accepted as an skin equivalent of full thickness. Science 1981;271:1052-1054.

25. O'Connor NE., Mulliken J.B, Banks-Schlegel S. Grating of burns with cultured epithelium prepared from autologous epidermal cells. Lancet 1981;1:75-78.

26. Gallico GG, O’Connor NE, Compton CC, Kehinde O, Green H. Permanent coverage of large burn wounds with autologous cultured human epithelium. New Engl J Med 1984; $311(7): 448-451$.

27. Cilento BG, Freeman MR, Schneck FX, Retik AB, Atala A Phenotypic and cytogenetic characterization of human bladder urothelia expanded in vitro. J Urol 1994; 152:665670.

28. Liebert M, Wedemeyer G, Chang JH, Stein JA, McKeever PE, Carey TE, et al. Comparison of antigen expression on normal urothelial cells in tissue section and tissue culture J Urol 1990;144:1288-1292.

29. Rheinwald JG. Serial cultivation of normal human keratinocytes Methods Cell Biol 1980;21:229-254.

30. Alitalo K, Kuismanen E, Myllyla R, Kiistala U, AskoSeljavaara S, Vaheri A.. Extracellular matrix proteins of human epidermal keratinocytes and feeder 3T3 cells. J Cell Biol 1982;94:497-505.

31. Green H. Cyclic AMP in relation to proliferation of the epidermal cell: a new view. Cell 1978;15:801-811.

32. Freeman AE, Igel HJ, Herrman BJ, Kleinfeld KL. Growth and characterization of human skin epithelial cells cultures. In Vitro. 1976;12:352-362.
33. Navsaria H, Sexton C, Bouvard V, Leigh .M. Growth of keratinocytes with a 3T3 feeder layer: basic techniques. En Leigh I.M., Watt F.M. directores. Keratinocyte Methods. Cambridge University Press 1994. pp 2-12.

34. Hutton KAR, Trejdosiewicz LK, Thomas DFM, Southgate J. Urothelial tissue culture for bladder reconstruction: an experimental study. Urol. 1993;150:721-725.

35. Southgate J, Hutton KAR, Thomas DFM, Trejdosiewicz LK. Normal human urothelial cells in vitro: proliferation and induction of stratification. Lab Invest 1994;71:583594.

36. Lauer G. Autografting of feeder-cell free cultured gingival epithelium J Craniomaxillofac Surg. 1994;22(1):18-22.

37. Messing EM, Hanson P, Ulrich P, Erturk E. E. Epidermal growth factor interactions with normal and malignant urothelium: in vivo and in situ studies. J Urol. 1987;138: 1329-1335.

38. Dubeau L, Jones PA.. Growth of normal and neoplastic urothelium and response to epidermal growth factor in a defined serum free medium. Cancer Res 1987;47:21072112.

39. Petzoldt JL, Leigh IM, Duffy PG, Masters JR. Culture and characterisation of human urothelium in vivo and in vitro. Urol Res 1994;22:67-74.

40. Freeman MR, Schneck FX, Soker S. et al. Human urothelial cells secrete and are regulated by heparin-binding epidermal growth factor-like growth factor (HB-EGF). J. Urol 1995; 153:307A. Abstract 316.

41. Freeman MR, Yoo JJ, Raab G, et al. Heparin-binding epidermal growth factor-like growth factor is an autocrine growth factor for human urothelial cells and is synthetisized by epithelial and smooth muscle cells in the human bladder. J Clin Invest 1997;99:1028-1036.

42. Tobin MS, Freeman MR, Schneck FX, Klagsbrun M, Atala A. Growth factor biology of human uroepithelial cells grown under serum free conditions. J Urol 1995;153:406A. Abstract 712 .

43. Atala A, Yoo JJ, Raab G, Klagsbrun M, Freeman MR. Regulated secretion of an engineering growth factor by human urothelial cells in primary culture. J. Urol 1996; 155: 336A. Abstract 101.

44. Fujiyama C, Masaki Z, Sugihara H.. Reconstruction of the urinary bladder mucosa in three-dimensional collagen gel culture: fibroblast-extracellular matrix interactions on the differentiation of transitional epithelial cells. J Urol 1995; 153:2060-2067.

45. Ueda M, Ebata K, Kaneda T. In vitro fabrication of bioartificial mucosa for reconstitution of oral mucosa: basic research and clinical application. Ann Plast Surg 1991;27:540549.

46. Tobin MS., Freeman MR, Atala A. Maturational response of normal human urothelial cells in culture is dependent on extracellular matrix and serum additives. Surg Forum 1994;45:786-789.

47. Scriven SD, Booth C, Thomas DF, Trejdosiewicz LK, Southgate J. Reconstitution of human urothelium from monolayer cultures. J Urol 1997;158:1147-1152.

48. Martins-Green M. Dynamics of cell-extracellular matrix interactions. En Lanza RP, Langer R, Vacanti JP. editores. Principles of tissue engineering. $2^{\underline{a}}$ edition. San Diego, California. Academic Press. 2000. pp 33-48.

49. Boyce ST, Skin substitutes from cultured cells and collagen-GAG polymers. Med Biol Eng Comput. 1998;36:791800 . 
50. Orgill DP, Buttler C, Regan JF, Barlow MS. Yannas IV. Compton CC. Vascularized collage-glycosaminoglycan matrix provides a dermal substrate and improves take of cultured epithelia autografts. Plast Reconstr Surg 1998; 102(2):423-429.

51. Meana A, Iglesias J, del Río M, Larcher F, Madrigal B, Fresno MF. Large surface of cultured human epithelium obtained on a dermal matrix based on a lived fibroblast containing fibrin gels. Burns 1998; 24(7): 621-630.

52. Horch RE, Bannasch H, Kopp J, Andree C, Stark GB. Single cell suspension of cultured human keratinocytes in fibrin glue reconstitutes the epidermis Cell Transplant. 1998;7:309-317.

53. Lam PK, Chan ES, Yen RS, Lau HC, King WW. A new system for the cultivation of keratinocytes on a cellular human dermis with the use of fibrin glue and 3T3 feeder. J Burn Care Rehabil 2000;21:1-4.

54. Wechselberger G, Bauer T, Meirer R, Piza-Katzer H, Lille S, Russell RC, et al. Muscle prelamination with urothelial cell cultures via fibrin glue in rats. Tissue Eng 2001 7(2):153-159.

55. Wechselberger G, Schoeller T, Roth AC, Lille S, Russell RC. Transplantation of autologous cultured urothelium cells onto a prefabricated capsule in rats. En Stark G.B, Horch A.C, Tanczos E. Biological matrices and tissue reconstruction. Springer-Verlag 1998. pp 125-134.

56. Wechselberger G, Bauer T, Meirer R, Piza-Katzer H, Lille S, Russell RC, et al. Muscle prelamination with urothelial cell cultures via fibrin glue in rats. Tissue Eng 2001;7(2):153-159.

57. Schoeller T, Wechselberger G, Lyons S, Otto A, Russell RC. Urothelial cell culture behaviour in fibrin glue compared to conventional culture medium. En Stark GB, Horch AC, Tanczos E. Biological matrices and tissue reconstruction. Springer-Verlag 1998. pp 125-134.

58. Schoeller T, Lille S, Bauer T, Piza-Katzer H, Wechselberger G. Gracilis muscle flap with a tissue engineered lining for experimental bladder wall reconstruction. BJU Int 2001; 88(1): 104-109.
59. Schaefer BM, Back W, Kramer M.D, Schober C, Waag K.L, Lorenz C. Autologous transplantation of urothelium into demucosalized gastrointestinal segments. En Stark G.B, Horch A.C, Tanczos E. Biological matrices and tissue reconstruction. Springer-Verlag 1998. pp 125-134.

60. Bach AD, Bannasch H, Galla TJ, Bittner KM, Stark GB. Fibrin glue as matrix for cultured autologous urothelial cells in urethral reconstruction. Tissue Eng 2001;7:4553.

61. Schoeller T, Lille S, Stenzl A, Ninkovic M, Piza H, Otto A, et al. Bladder reconstruction using a prevascularized capsular tissue seeded with urothelial cells. J Urol 2001;165(3): 980-985.

62. Staack A, Alexander T, Merguerian P, Terris MK. Organ and species specificity in the stimulation of transitional epithelial cell growth by fibroblasts. Eur Urol 2001;39(4): 471-477.

63. Atala A. Tissue engineering of artificial organs. J.Endourol 2000;14(1):49-57.

64. Yoo JJ, Satar N, Retik AB Atala A. Ureteral replacement using biodegradable polymer scaffolds seeded with urothelial and smooth muscle cells. J Urol 1995;153:375A. Abstract 585.

65. Atala A. Engineering tissues and organs. Curr Opin Urol 1999;9(6):517-526.

66. Oberpenning F, Meng J, Yoo JJ, Atala A. De novo reconstitution of a functional mammalian urinary bladder by tissue engineering.. Nat Biotechnol 1999;17(2):149-155.

Dr. E. de Diego Rodríguez

(Trabajo recibido el 19 de octubre 2005) 